\title{
Ethno-Design as a Means of Forming Technological and Artistic Competences of Future Technology Teachers and Vocational Educators
}

\author{
Akimbek Mederhanovich Muhadiev ${ }^{1}$, Perizat Meiramovna Aitmukhanova ${ }^{2}$, Baimurat Ermagambetovich Ospanov ${ }^{1}$, \\ Zinidin Nastajievich Isnyazov ${ }^{3}$ and Zhalgasbek Zhapparbekovich Beisenbekov ${ }^{4}$ \\ ${ }^{1}$ Abai Kazakh National Pedagogical University, Kazakhstan. \\ ${ }^{2}$ Satbayev University, Kazakhstan. \\ ${ }^{3}$ National Academy of Arts named after T.K.Jurgenov, Kazakhstan. \\ ${ }^{4}$ International Kazakh-Turkish University named after Khoja Akhmed Yassawi, Kazakhstan.
}

\begin{abstract}
This article analyses the constructive solution and aesthetic design of the yurt as a unique invention of mankind. Due to its convenience and practicality, the yurt fully meets the needs of the nomads. It is quickly assembled and easily disassembled in one hour or less by the forces of one family. The yurt is easily transported by camel, horse or oxen; its felt cover provides protection from the rain, wind and cold. The hole at the top of the dome is used for daylight and allows using the hearth.

The article describes the assembling of the yurt and the installation of its shanyrak. The shanyrak is mounted on the right side of the yurt. The frontal side of the shanyrak is set directly opposite the mandaisha, supported with a wooden pole (baqan) with a forked upper end. The other end of the pole is put in the center of the yurt helping to lift the shanyrak. After that, the dome poles (ýyq) are pierced at special holes along its edges and tied to the edges of the core (kerege), thereby creating the roof of the yurt. The image and elements of the yurt, its functional and compositional uniqueness is of great importance in the history of architecture and fine art.
\end{abstract}

Keywords: Turkic-speaking peoples, shanyrak, installation, ýyq, kerege, compositional uniqueness

On the territory of today's Kazakhstan, some unique buildings have been discovered that are identical to those that have been used by the nomadic peoples and tribes of Asia for millennia. For example, near the Alybay aul of the Katon-Karagai district of the East Kazakhstan region, an image of a tentshaped dwelling was discovered with a clear functional division into male and female parts. A man and a woman were depicted inside a yurt-like dwelling with visual division by gender and a vertically installed chimney. There were yurts in the neighborhood - the ancient Turkic horsemen, horses, camels, sheep, and cows that personified wealth [1].

The prototype of the yurt is a multifaceted or round structure with frame-lattice pole walls and a canonical coating. A cauldron for cooking was set in the center of the yurt. A round hole for light and smoke was located at the very top of the dome. On cold or rainy days, the upper hole of the yurt was covered with "túndik" - a high-quality grade of the felt cloth [2]. It was the folding frame-lattice wall-kerege, sliding apart, found on the territory of Kazakhstan, that became the fundamental difference between the yurt and its predecessors that looked like a simple and ordinary hut (Figure 1). The final design of the yurt was established in the Hun-Turkic period with the appearance of the most important domeshaped element - the shanyrak (Figure 2).

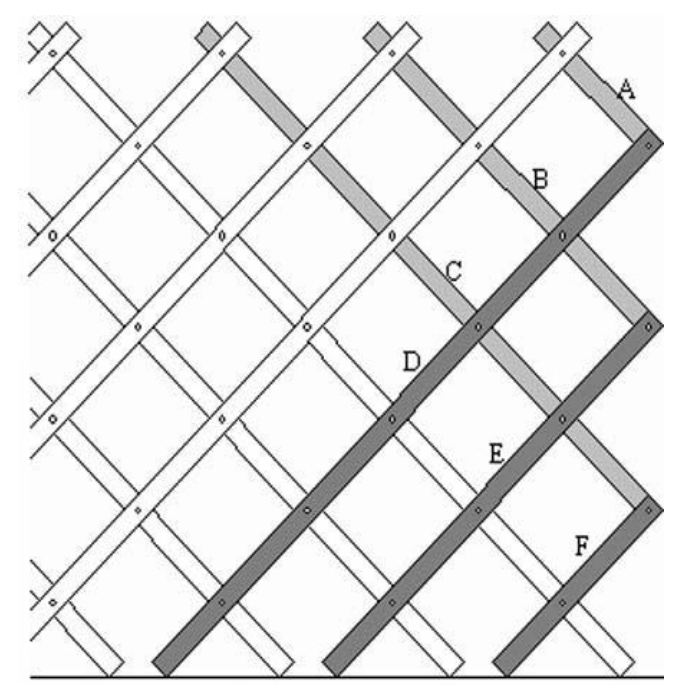

Fig. 1. The yurt easily ventilated from any side through lattice walls - kerege

Based on archaeological research, the first prototype of the yurt existed seven thousand years ago. The nomad's dwelling is "industrial" in its own way - the standard, high installation speed, transportability. The brilliant connoisseur of the nomadic cultures of Eurasia, the ethnologist S. I. Rudenko wrote that the Kazakh yurt has not been "surpassed by any of 
the nomadic peoples from a constructive point of view and is the most perfect of portable dwellings" [3, 4].

The yurt astonishes for its completeness and perfection. For many millennia, every single component was intently and thoroughly polished until it reached the ideal form without frills [5]. The famous French architect Le Corbusier admired the completeness, functionality, versatility and interchangeability of parts of the yurt as well as its laconic design. It was he who considered the yurt as one of the prototypes of his concept "house - a car for housing" [6].

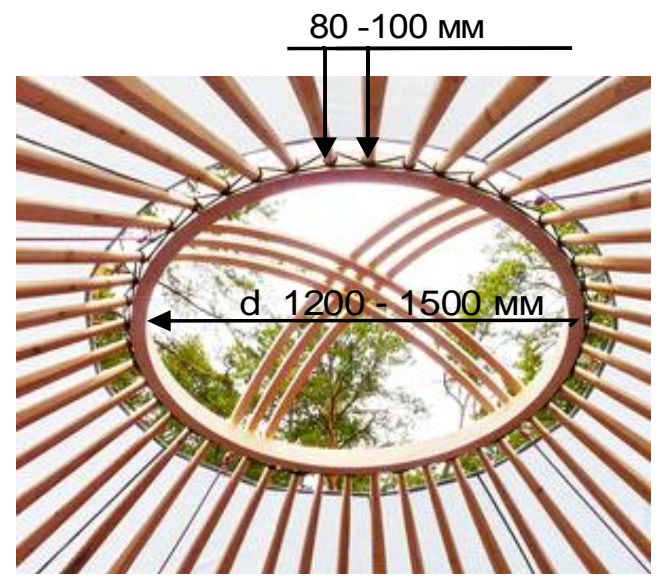

Fig. 2. A lattice circle, a hole in the center of the domeshanyrak

The yurt that arose several thousand years ago remains relevant in our time. Light weight, compactness, transportability, seasonability, and functionality of parts, combined with low cost, make this dwelling competitive in the market of prefabricated, lightweight structures (Figure 3). One should also note its affordable operational cost installation and maintenance do not require special qualifications, and compactness and transportability is the basis of small storage costs [7,8]. At the same time, the cost of the yurt is 3-4 times lower compared to other modern quickly erected structures.

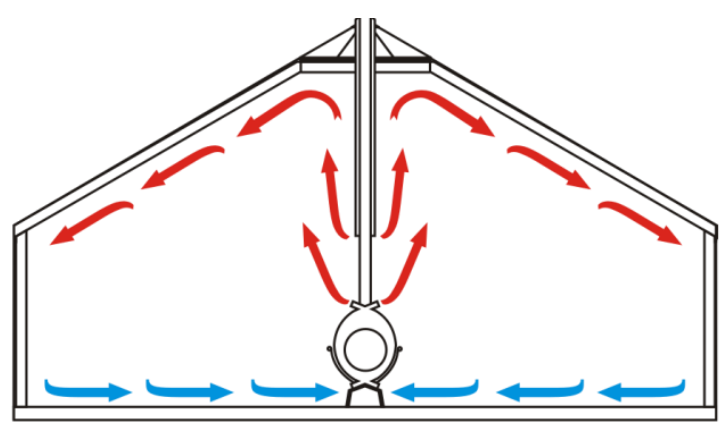

Fig. 3. Perfect air circulation through lattice walls creating the necessary coolness in the summer period
The felt yurt is the dwelling of Kazakhs, Mongols, Turkmens, Bashkirs, Tatars, Buryats, Kyrgyzs and many Turkic-speaking peoples of Eurasia, which has been improved and refined for centuries. The basis of its frame is made up of folding and sliding lattice walls - "kerege" (Figure 4). With the help of horsehair ropes, the dome poles (ýyq) are attached, ending with a massive hoop (shanyrak) at the top. The frame at the top is covered with gray, white, and brown felt (kiíz). The yurt with a white felt cover was considered sacred - it was complemented by green, red, blue, and brown patterns (onýórnek) and embroideries (baskýry), which made the dwelling look festive and solemn (Figure 5). The entrance (bosag a), consisting of an external felt curtain and an internal wooden door, is painted red and decorated with an ornament symbolizing happiness and longevity. The yurt was also a simple dwelling of nomads, a temple and a palace. The basis of many cult Turkic and Mongolian buildings was formed by the composition of such a yurt with laconicism, clarity, and stability of its forms [9].

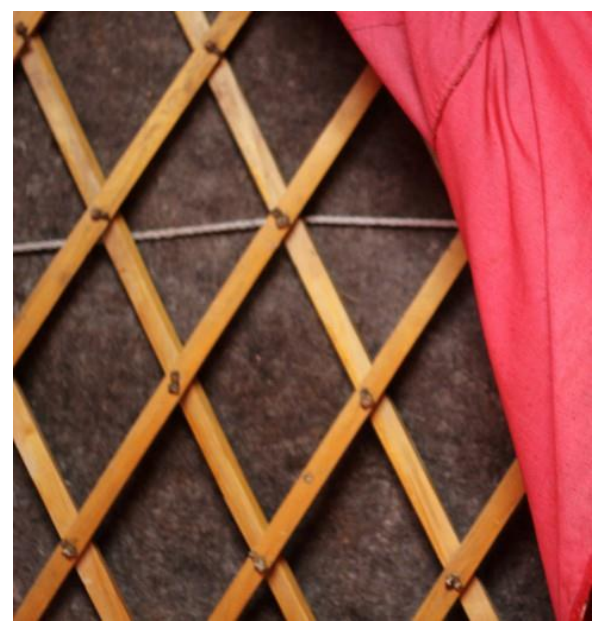

Fig 4. Kerege - a rope, folding lattice walls and a large piece of felt covering the structure

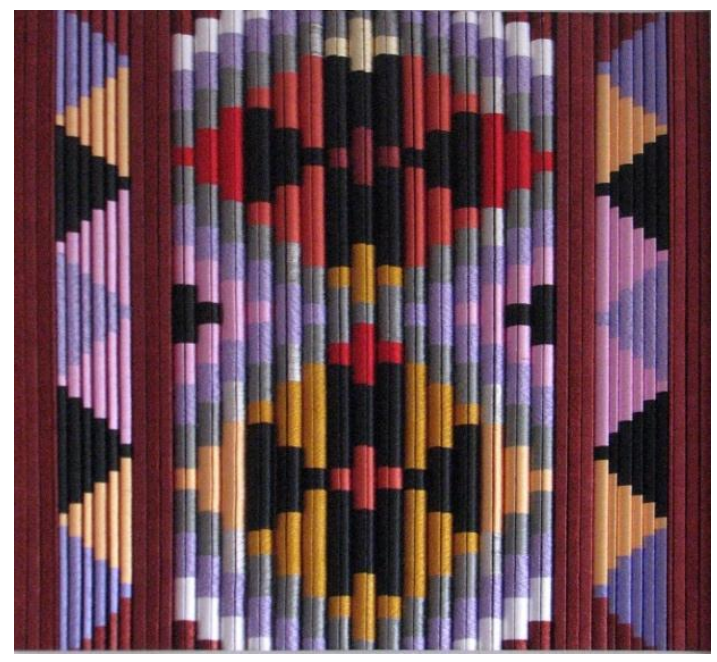

Fig. 5. Sh11 - a patterned mat wrapping the base of the yurt kerege 
According to researchers, the shanyrak was associated with the firmament. It was the line between outer and inner space. Through the shanyrak, the inhabitants of the yurt communicated with sacred celestial bodies: the sun, moon and stars. In the first months after the wedding, the bride owed a duty to get up at sunrise and open the felt cover (túndik) over the shanyrak. They saw a deep meaning in this procedure.

The shanyrak was a family heirloom, a symbol of procreation. It was passed down from generation to generation. The contour outlines of the shanyrak - a cross in a circle - is a sign of the eternal movement of the sun, a symbol of evolution [10]. The yurt itself also had a sacred meaning. It symbolized the unity of the universe and the cosmos, the comprehended space.

For ancient nomads, the yurt personified the unity of the people with nature. Forming a yurt, a man created it in his own likeness. It is no coincidence that all the structures and elements of the yurt have Kazakh names of the anatomy of the human body. For example, úidiń sú1egi (bone - the frame of the yurt), mandaisha (forehead - the upper part of the jamb). In addition to the symbolic meaning, the yurt had a household nature [11]. Usually the number of roof rafters is 60 , that is, the number of years of the absolute circle of the lunar calendar. Starting from the north in the direction of the movement of the sun, the dome is divided into 12 sectors, and the time of day was set according to which one the sunlight from the shanyrak fell. In other words, the yurt is both a calendar and a clock.

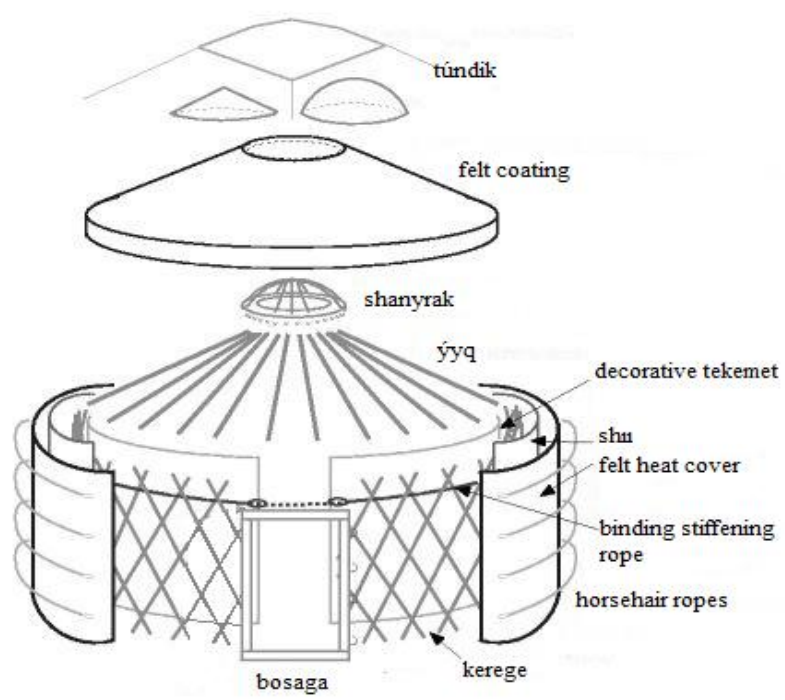

Fig 6. The structure of the yurt

The yurt is transportable - it is assembled or disassembled in no more than an hour. The structure of the yurt, consisting of a wooden lattice and wool felt, while maintaining a constant thermal regime inside the dwelling, plays the role of a temperature regulator. In scorching summer, one can create circular ventilation in the yurt, by slightly raising the felt cloth below: as a result, the air will circulate and create the necessary coolness. Such a unique ability is extremely significant: in some regions of Kazakhstan the air temperature in summer is $+45^{\circ} \mathrm{C}$, and in winter $--35^{\circ} \mathrm{C}$. The yurt is resistant to any natural disasters - its structure can withstand both hurricanes and earthquakes. The prefabricated demountable construction of the yurt is adapted for transportation by pack animals. The total weight of the yurt with furniture is about $350-500 \mathrm{~kg}$, which is the carrying capacity of only one camel.

The interior of any dwelling is formed by decorative art objects, organically combined with its architecture. Household items made from various materials carry their utilitarian and artistic functions and are combined into a single system only in the interior of the dwelling, the creation of which determines the aesthetic tastes and cultural indicators of the individual and the people as a whole. Another representative of Renaissance culture and aesthetics A. Dürer noted that "... something good is taken from many beautiful things, just as honey is gathered from many flowers." The study of the artistic value and constructiveness of the interior design of the yurt, as well as the identification of its traditional images from aesthetic positions are of great practical importance for the development and organization of the internal space in modern architecture and design $[12,13]$.

There were numerous kinds of yurts - from compact yurts for a simple nomad family to huge ones - palaces of the steppe rulers. The yurts of bais (rich landowners) consisted of 6-12 lattice walls (qanat) and accommodated 30-50 people. Both yurts for guests and newlyweds (otaý-úi) can be attributed to the rich [14]. Wedding yurts were very beautiful with an abundance of ornaments and rich colors. There were also military camp yurts. The largest of them were called ablaisha, and the smallest - jolym-ú1. There were special yurts for kitchens and warehouses. During the campaigns of Genghis Khan, there were yurts on wheels - kind of the ancestors of the current trailers [15].

Nowadays, there are two types of yurts - Turkic and Mongolian. The Turkic type of the yurt is used by Kyrgyzs, Kazakhs, and Turkmens, and the Mongolian is widespread in Buryatia, Kalmykia, Mongolia, Tuva, and Tibet. The main difference between them is the dome pole. In the Turkic yurt, this pole has a curve, while in the Mongolian it does not. Therefore, there are pillars in the center of the Mongolian yurt. Both types of yurts have their own advantages: the Turkic is more functional and solemn, while the Mongolian is more primitive.

\section{REFERENCES}

[1] Mukanov MS. The Kazakh yurt. Almaty, 1981: 224.

[2] Dzhanibekov U. The culture of Kazakh craft. AlmaAta: Oner, 1982.

[3] Gutnov A. The world of architecture. Moscow, 2015: 352.

[4] Kalybekova A. The folk wisdom of Kazakhs about education. Almaty, 2014. 
[5] Khan-Magomedov S.O. On the problem of national identity of the subject-spatial environment. Makhachkala, 2012.

[6] Flores H.I.A., Mena N.P. Cultural and Intercultural Education: Experiences of Ethnoeducational Teachers in Colombia. Australian Journal of Teacher Education, 43(7), Article 4, 2018. http://dx.doi.org/10.14221/ajte.2018v43n7.4

[7] Rosa M., Orey D.C. State of the Art in Ethnomathematics. In: Current and Future Perspectives of Ethnomathematics as a Program. ICME-13 Topical Surveys. Springer, Cham. 2016.

[8] Hajisoteriou Ch., Maniatis P., Angelides P. Teacher professional development for improving the intercultural school: an example of a participatory course on stereotypes, Education Inquiry, 10(2), 166188, 2019. DOI: $10.1080 / 20004508.2018 .1514908$

[9] Aitmukhanova P.M., Baikulakov N.T., Muhadiev A.M., Kisimisov Y.T., Kudabaeva C.I. The Use of Support Schemes in Teaching Architectural Design. International Journal of Engineering Research and Technology, 12(12), 2298-2302, 2019.

[10] Omarova N.K., Sherembaeva R.T. Sulfide copper ore flotation with «PS» reagent. Obogashchenie Rud, 2, 2015. DOI 10.17580/or.2015.02.03

[11] Sherembaeva R.T., Omarova N.K., Akimbekova B.B., Katkeeva G.L. Usage of new flotation agent "P" during sulfide copper ores flotation. Tsvetnye Metally, 6, 1216, 2014.

[12] Gülbahar Y. Improving the technology integration skills of prospective. The Turkish Online Journal of Educational Technology , 7(4), Article 8, 2008.

[13] Sherembaeva R.T., Omarova N.K., Akimbekova B.B., Mukhtar A.A. Chalcopyrite and bornite flotation in hallimond tube. Tsvetnye Metally, 4, 8-11, 2016. DOI 10.17580/tsm.2016.04.01

[14] Yezhova O., Gryn D. Objectives of preparation of future specialists in technological education from the standpoint of a competence-based approach. Fundamental and Applied Researches in Practice of Leading Scientific Schools, 28(4), 164-168, 2018. https://doi.org/https://doi.org/10.33531/farplss.2018.4. $\underline{29}$

[15] Zhanguzhinova, M. Formation of the professional competence of students - future teachers of vocational trainingin the system of higher education in Kazakhstan. Doctoral dissertation for the degree of Doctor of Pedagogy. Rezekne, 2017. 